\title{
Perbandingan Metode Klasifikasi pada Pengolahan Citra Mata Ikan Tuna
}

\author{
Toni Dwi Novianto ${ }^{1}$, I Made Susi Erawan ${ }^{1}$ \\ ${ }^{1}$ Loka Riset Mekanisasi Pengolahan Hasil Perikanan, Yogyakarta \\ Jl. Imogiri Barat KM 11,5 Jetis, Bantul, DI Yogyakarta \\ Email : noviantoni90@gmail.com
}

\begin{abstract}
Fish eye color is an important attribute of fish quality. The change in eye color during the storage process correlates with freshness and has a direct effect on consumer perception. The process of changing the color of the fish eye can be analyzed using image processing. The purpose of this study was to obtain the best classification method for predicting fish freshness based on image processing in fish eyes. Three tuna fish were used in this study. The test was carried out for 20 hours with an eye image every 2 hours at room temperature. Fish eye image processing uses Matlab R.2017a software while the classification uses Weka 3.8 software. The image processing stages are taking fish eye image, segmenting ROI (region of interest), converting $R G B$ image to grayscale, and feature extraction. Feature extraction used is the gray-level co-occurrence matrix (GLCM). The classification techniques used are artificial neural networks (ANN), k-neighborhood neighbors ( $k$-NN), and support vector machines $(S V M)$. The results showed the value using $A N N=0.53, k-N N=0.83$, and $S V M=0.69$. Based on these results it can be determined that the best classification technique is to use the k-nearest neighbor $(k-N N)$.
\end{abstract}

Keywords: classification, fish eye, GLCM, image processing, tuna

\begin{abstract}
Abstrak: Warna mata ikan merupakan atribut penting pada kualitas ikan. Perubahan warna mata ikan selama proses penyimpanan berhubungan dengan tingkat kesegaran dan memiliki efek langsung pada persepsi konsumen. Proses perubahan warna mata ikan dapat dianalisis menggunakan pengolahan citra. Tujuan penelitian ini adalah mendapatkan metode klasifikasi terbaik untuk memprediksi kesegaran ikan berbasis pengolahan citra pada mata ikan. Tiga ekor ikan tuna digunakan dalam penelitian ini. Pengujian dilakukan selama 20 jam dengan pengambilan citra mata setiap 2 jam pada suhu ruang. Pengolahan citra mata ikan menggunakan software matlab R.2017a sedangkan pengklasifiannya menggunakan software Weka 3.8. Tahapan pengolahan citra meliputi pengambilan citra mata ikan, segmentasi ROI (region of interest), konversi citra RGB menjadi grayscale, dan ekstraksi fitur. Ekstraksi fitur yang digunakan yaitu gray-level co-occurrence matrix (GLCM). Teknik klasifikasi yang digunakan yaitu, artificial neural network (ANN), k-nearest neighbors (k-NN), dan support vector machine (SVM). Hasil penelitian menunjukkan nilai korelasi menggunakan $\mathrm{ANN}=0,53, \mathrm{k}-\mathrm{NN}=0,83$, dan $\mathrm{SVM}=0,69$. Berdasarkan hasil tersebut dapat disimpulkan teknik klasifikasi terbaik adalah menggunakan $k$-nearest neighbors (k$\mathrm{NN})$.
\end{abstract}

Kata kunci: GLCM, klasifikasi, mata ikan, pengolahan citra, tuna

\section{PENDAhULUAN}

Ikan merupakan komoditas pangan yang mudah mengalami penurunan kualitas. Kesegaran adalah parameter penting dalam menentukan kualitas ikan dan produk perikanan. Kebanyakan konsumen menganggap kesegaran ikan merupakan bagian yang dapat menunjukkan rasa dan keamanan ikan. Ikan menunjukkan beberapa perubahan fisik yang jelas selama proses penurunan kesegaran seperti warna, tekstur, bau, kulit, sisik, mata, insang dan perut. Perubahan tersebut dapat digunakan untuk menentukan kesegaran ikan secara tunggal (Isaac, 2016). Konsumen dan pedagang umumnya menggunakan kondisi mata ikan untuk menentukan tingkat kesegaran ikan. Hal ini karena mata ikan mengalami perubahan yang terlihat jelas setelah ikan 
mati (Huss, 1988). Contohnya adalah penurunan tekanan intra-okuler mata karena kehilangan air, hal ini menghasilkan warna mata yang keruh. Sifat pembiasan cahaya pada mata ikan adalah hasil dari peningkatan konsentrasi komponen terlarut pada cairan mata ikan (Yapar et al, 1998).

Analisis citra merupakan alat yang digunakan untuk mengevaluasi data berupa gambar dan menganalisis perubahan warnanya menggunakan perangkat lunak sehingga dapat digunakan untuk menentukan kesegaran ikan (Manesatti, 2010). Analisis citra terdiri dari tiga langkah utama yaitu pengolahan level dasar (akuisisi citra dan proses awal), pengolahan level menengah (segmentasi dan pengukuran objek), dan pengolahan citra lanjutan (Brosnan dan Sun, 2004). Dengan menerapkan analisa citra di bidang pengolahan hasil perikanan maka akan mendapatkan sebuah metode pemeriksaan kualitas ikan yang tidak merusak ikan dan tidak berbahaya bagi penguji dengan waktu yang relatif cepat (Kurniawan, 2016).

Klasifikasi data adalah suatu proses memisahkan serta mengelompokan sekumpulan data dengan kumpulan data yang lain. Menurut Han dan Kamber (2013) klasifikasi data memiliki dua tahap proses. Pertama yaitu membangun suatu model atau pola berdasarkan serangkaian kelas data yang selanjutnya akan di klasifikasikan. Tahap pertama ini juga sering disebut dengan tahap training atau proses pembelajaran, proses pembangunan model ini dengan cara menganalisis data training yang ada. Pada umumnya proses pembangunan model ini diterjemahkan ke dalam bentuk classification rules, decision tree, atau model matematika lainnya. Selanjutnya pada tahap kedua yaitu proses pengklasifikasian menggunakan data testing, model yang telah ditentukan akan digunakan untuk memprediksi data yang belum diketahui labelnya. Metode klasifikasi yang sering digunakan untuk menentukan kesegaran ikan adalah artificial neural networks (ANN), support vector machine (SVM), dan k-nearest neighbour (k-NN).

Penelitian mengenai perbandingan metode klasifikasi hasil pengolahan citra pada ikan telah dilakukan antara lain oleh Rohani (2019) yang membandingkan metode klasifikasi artificial neural networks (ANN) dan support vector machine (SVM) pada pengolahan citra telur ikan trout dan Rahman et al (2016) yang membandingkan metode klasifikasi SVM, LDA (Linear Discriminant Analysis) dan SIMCA (Soft Independent Modeling Of Class Analogy) pada pengolahan citra mata ikan untuk menentukan kesegaran ikan Japanese Dace. Tujuan penelitian ini adalah mendapatkan metode klasifikasi terbaik untuk memprediksi kesegaran ikan berbasis pengolahan citra pada mata ikan.

\section{METODE PENELITIAN}

\subsection{Bahan}

Bahan yang digunakan adalah ikan tuna (Thunnus sp.) hasil tangkapan nelayan Pelabuhan Perikanan Pantai (PPP) Sadeng, Kabupaten Gunungkidul, Daerah Istimewa Yogyakarta dengan ukuran panjang rata-rata $30 \mathrm{~cm}$ dan berat $1-2 \mathrm{~kg}$. Ikan tuna dibawa menggunakan cool box yang diberi es curah untuk mempertahankan suhu dingin selama transportasi. Kamera yang digunakan adalah tipe Olympus. Tempat untuk pengambilan foto mata ikan pada kotak akrilik ukuran 25 x $15 \times 15 \mathrm{~cm}$ dengan pencahayaan terkontrol.

\subsection{Metode}

\subsubsection{Pengolahan Citra}

Rangkaian penelitian dimulai dengan akuisisi data citra mata ikan di dalam kotak khusus. Penggunaan kotak khusus ini untuk mendapatkan lingkungan yang sama sehingga meminimalisir variasi yang timbul pada citra mata ikan. Ikan disimpan pada suhu ruang selama 
20 jam. Pengambilan citra mata ikan dilakukan setiap dua jam sekali. Software yang digunakan untuk pengolahan citra adalah matlab 2017b. Citra mata ikan yang diperoleh akan melalui dua tahapan pengolahan citra yaitu preprocessing untuk meningkatkan kualitas gambar dan ekstraksi fitur citra mata ikan. Proses preprocessing meliputi akuisisi data, penyesuaian histogram citra, croping dan resize,dan segmentasi ROI (Region of Interest). Tahapan ektraksi fitur menggunakan metode Gray Level Co Occurent Matrix (GLCM). Hasil ekstraksi fitur GLCM adalah contrast, correlation, energy dan homogenity.

Contrast : mengukur intensitas kontras antara piksel dan tetangganya di atas seluruh gambar, mengevaluasi variasi lokal.

$$
\text { Contrast }=\sum_{i} \sum_{j}(i-j)^{2} p_{i j}
$$

Ini berkisar dari 0 (untuk gambar konstan) ke akar kuadrat rata-rata ukuran GLCM -1.

Correlation : mengukur bagaimana sebuah piksel berkorelasi dengan tetangganya seluruh gambar, mengevaluasi kemungkinan terjadinya gabungan dari pasangan piksel yang ditentukan.

$$
\text { Correlation }=\sum_{i} \sum_{j} \frac{(i-\mu i)(j-\mu j)}{\sqrt{\left(\sigma i^{2}\right)\left(\sigma j^{2}\right)}} p_{i j}
$$

di mana $\mathrm{m}$ dan $\mathrm{s}$ adalah nilai rata-rata dan standar deviasi. Ini berkisar antara 1 dan 1 , yang berdiri dengan sempurna citra negatif atau berkorelasi positif.

Energy, juga dikenal sebagai keseragaman atau momen kedua angular: itu mengembalikan jumlah elemen kuadrat di GLCM

$$
\text { Energy }=\sum_{i} \sum_{j} p_{i j}^{2}
$$

Ini berkisar dari 0 hingga 1, menjadi 1 nilai untuk gambar konstan.

Homogenity : mengukur kedekatan distribusi elemen dalam GLCM ke GLCM diagonal

$$
\text { Homogenity }=\sum_{i} \sum_{j} \frac{1}{1+(i-j)^{2}} p_{i j}
$$

Ini berkisar dari 0 hingga 1 . Homogenitas adalah 1 untuk GLCM diagonal.

\subsubsection{Support Vector Machine (SVM)}

Support vector machine (SVM) adalah suatu metode atau algoritma untuk melakukan klasifikasi maupun prediksi. Prinsip kerja dari metode ini adalah mencari ruang pemisah yang paling optimal dari suatu dataset dalam kelas yang berbeda. Fitur unik dari SVM adalah algoritma ini didasarkan pada teori pembelajaran statistik dan prinsip minimalisasi risiko struktural yang mencoba mengurangi batas atas generalisasi kesalahan daripada mengurangi kesalahan pelatihan lokal. Ini adalah perbedaan paling penting dari prinsip yang umum digunakan minimalisasi risiko empiris, yang digunakan oleh metode machine learning konvensional (Meenal, 2017). Berbeda dengan strategi neural network yang berusaha mencari 
hyperplane pemisah antar kelas, SVM berusaha menemukan hyperplane yang terbaik pada input space. Prinsip dasar. SVM adalah klasifikasi linear, dan selanjutnya dikembangkan agar dapat bekerja pada problem non-linear dengan memasukkan konsep kernel trick pada ruang kerja berdimensi tinggi.

\subsubsection{Artificial Neural Network (ANN)}

Artificial Neural Network (ANN) dan pemodelan statistik adalah dua pendekatan pemodelan prediktif yang berbeda. Dasar dibalik penggunaan salah satu alat adalah belajar dari data. Model ANN telah digunakan untuk berbagai macam aplikasi seperti pengenalan pola, prediksi, perkiraan, optimisasi dan simulasi. Pada model statistik konvensional pendekatan didasarkan pada hubungan linear antara input dan output dalam bentuk persamaan matematika. Jadi model statistik empiris ini adalah matematika intensif dan berdasarkan estimasi koefisien. Biasanya pemodelan statistik diterapkan untuk data yang lebih kecil dengan atribut yang lebih sedikit. Namun ANN mampu belajar dari set data besar dengan atribut tambahan. Keuntungan dari teknik ANN adalah tidak memerlukan pengetahuan perhitungan matematis antara parameter dan memberikan solusi yang lebih baik untuk masalah yang berbeda.

\subsection{4. $k$-Nearest Neighbour $(k-N N)$}

$k$-Nearest Neighbour (k-NN) merupakan algoritma paling sederhana diantara algoritma lainnya dalam hal memprediksikan suatu kelas pada suatu sampel. Untuk mengklasifikasikan suatu kelas, k-NN bekerja berdasarkan jarak terdekat ketetanggaan antar objek dengan cara sebagai berikut (Sudha, 2012):

a. Menghitung jarak dari seluruh training vectors to test vectors.

b. Ambil nilai k yang paling dekat nilai vektornya.

c. Hitung nilai rata-ratanya. Jika nilai $\mathrm{k}=1$, maka objek diasumsikan sebagai anggota kelas dari tetangga terdekatnya.

Nilai k terbaik tergantung dari banyaknya data. Secara umum semakin tinggi nilai k makan akan mengurangi pengaruh noise pada proses klasifikasi. Untuk menghitung jarak pada seluruh data latih, pengukurannya dapat dilakukkan dengan beberapa metoda seperti Euclidean distance, Cityblock distance, Cosine distance, Correlation, Hamming distance (Aulia, 2015).

\subsubsection{Perbandingan Algoritma Machine Learning}

Terdapat langkah tambahan untuk mendapatkan pengaturan parameter terbaik dari masingmasing metode klasifikasi. Langkah tersebut adalah dengan menjalankan $k$-fold cross validation. $k$-fold cross validation berfungsi untuk membagi data latih dan uji. Pada penelitian ini digunakan $k$-fold cross validation $10(\mathrm{k}=10)$, yang artinya data akan dibagi 10 bagian dimana 1 bagian merupakan data uji dan sisanya data latih. Kemudian diambil 1 bagian lain menjadi data uji dan 9 lain menjadi data latih lagi, terus seperti itu hingga 10 bagian tersebut pernah dijadikan data uji (Nugraha, 2018). Untuk membandingkan performa dari masingmasing algoritma digunakan nilai koefisien korelasi dan RMSE (root mean square error). Semua model algoritma dijalankan menggunakan software open source Weka 3.8. Agar mendapatkan performa yang optimal dari masing-masing algoritma maka dilakukan analisis sensitivitas terlebih dahulu. Analisis sensitivitas adalah metode mempelajari perilaku model dan menilai signifikansi setiap input parameter pada nilai-nilai variabel output dari model. Tujuan utama dari analisis sensitivitas adalah untuk mengetahui bagaimana data keluaran dipengaruhi oleh variabilitas dari data input. Dengan bantuan analisis semacam ini, dimungkinkan untuk mengevaluasi parameter input mana yang dianggap paling signifikan dan 
paling tidak signifikan untuk model prediksi. Pada bagian ini digunakan analisis regresi untuk mendapatkan parameter input yang paling berpengaruh.

\section{PEMBAHASAN}

Penelitian ini menggunakan tiga ekor sampel ikan tuna yang diamati bagian mata kirinya. Pengambilan citra mata ikan dilakukan setiap dua jam sekali selama 20 jam. Gambar 1 menunjukkan adanya perubahan warna mata ikan dari pengamatan jam ke 0 sampai jam ke 20 . Warna mata ikan berubah dari bersih dan jernih menjadi merah dan keruh seiring waktu penyimpanannya. Hasil ini sesuai dengan jenjang kriteria mutu ikan menurut Soekarto 1985 yaitu semakin menurunnya kualitas ikan ditandai dengan semakin keruh kornea warna mata ikan.
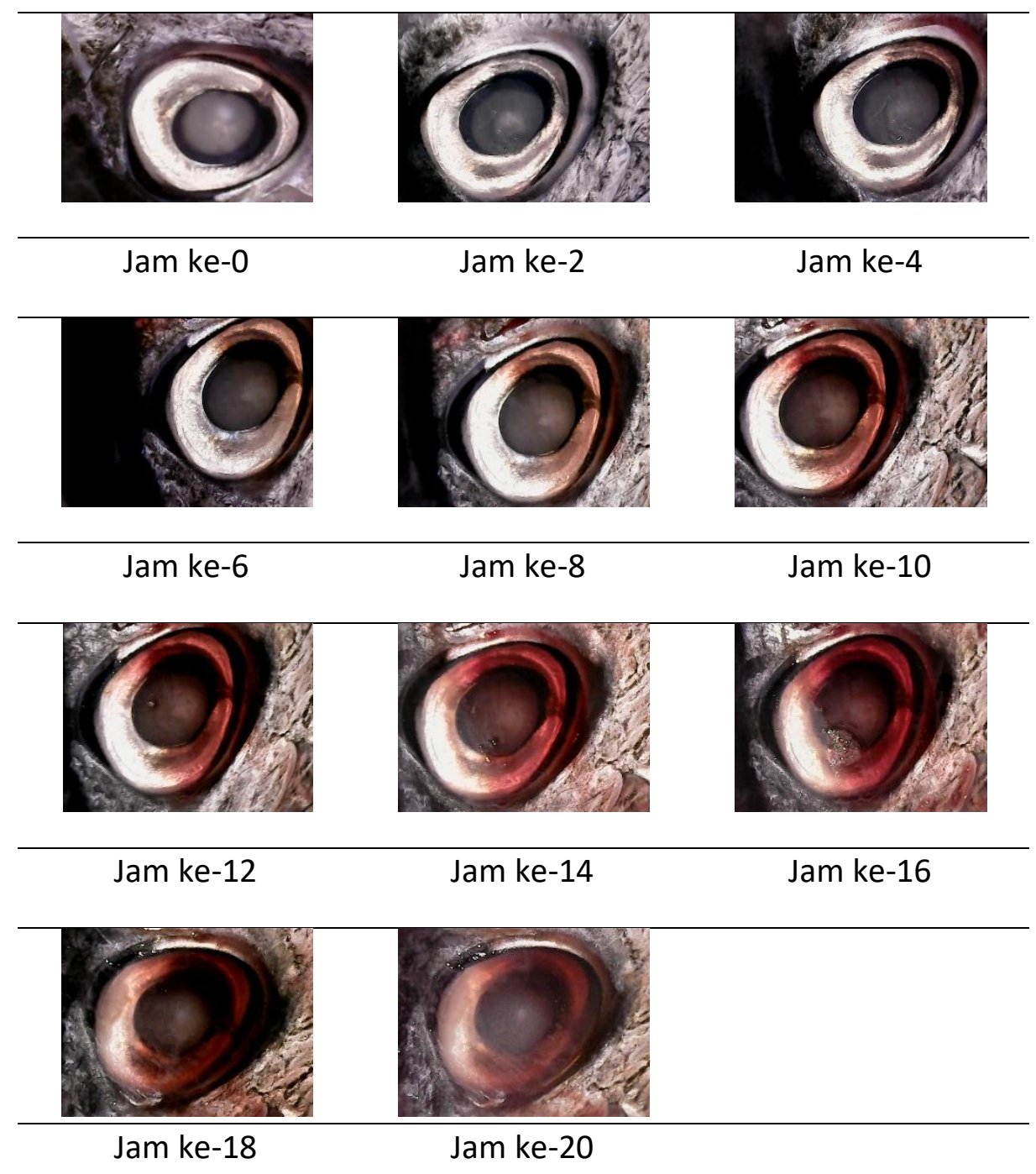

Gambar 1. Hasil pengamatan citra mata ikan tuna selama 20 jam

Hasil citra mata ikan kemudian diolah menggunakan software mathlab seperti ditunjukkan pada Gambar 2. Selanjutnya dilakukan ektraksi fitur menggunakan GLCM sehingga menghasilkan parameter contrast, correlation, energy dan homogenity. Tren nilai parameter hasil ekstraksi fitur terhadap waktu pengamatan ditunjukkan pada Gambar 3. Nilai parameter hasil ekstraksi fitur selanjutnya dianalisis sensitivitasnya dengan cara diuji regresinya. Tabel 1 
menunjukkan hasil uji regresi pada masing-masing parameter hasil ektraksi fitur. Parameter correlation memiliki nilai korelasi (R) paling rendah yaitu 0,39 . Sedangkan parameter energy dan homogenity memiliki nilai korelasi yang sangat tinggi yaitu 0,96 dan 0,95 . Nilai korelasi semakin mendekati nol maka semakin berpengaruh signifikan terhadap akurasi hasil prediksi suatu model algoritma. Berdasarkan hasil tersebut maka parameter yang digunakan untuk memprediksi kesegaran ikan tuna model algoritma klasifikasi adalah contrast, energy, dan homogenity.

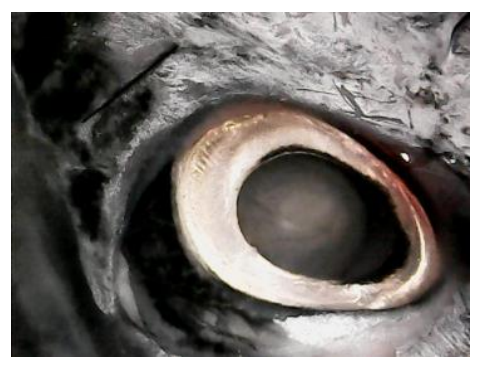

a.

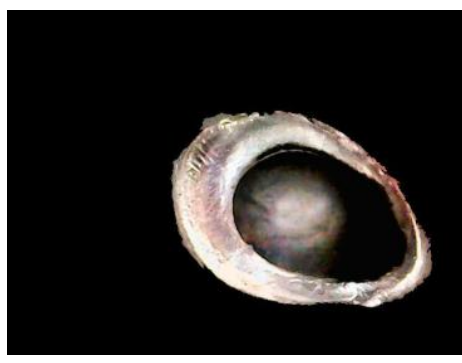

b.

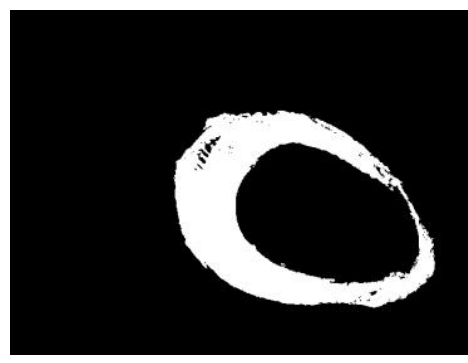

C.

Gambar 2. Hasil pengolahan citra mata ikan tuna

(a) Original, (b) Poly, (c) ROI

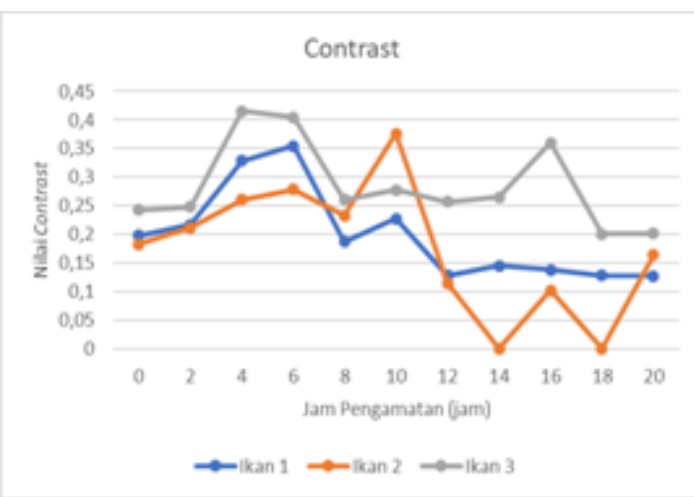

Correlation

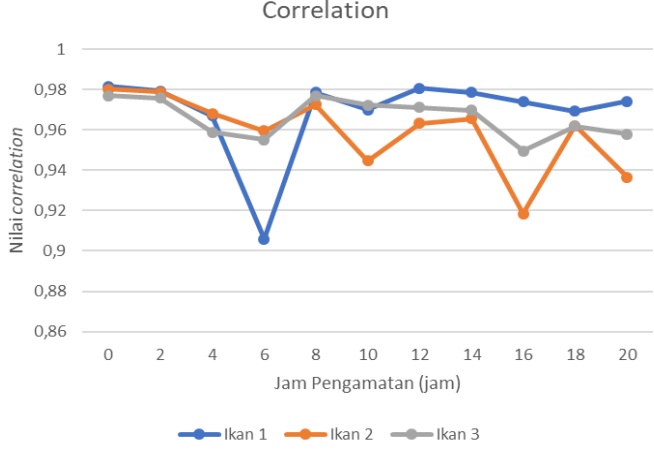

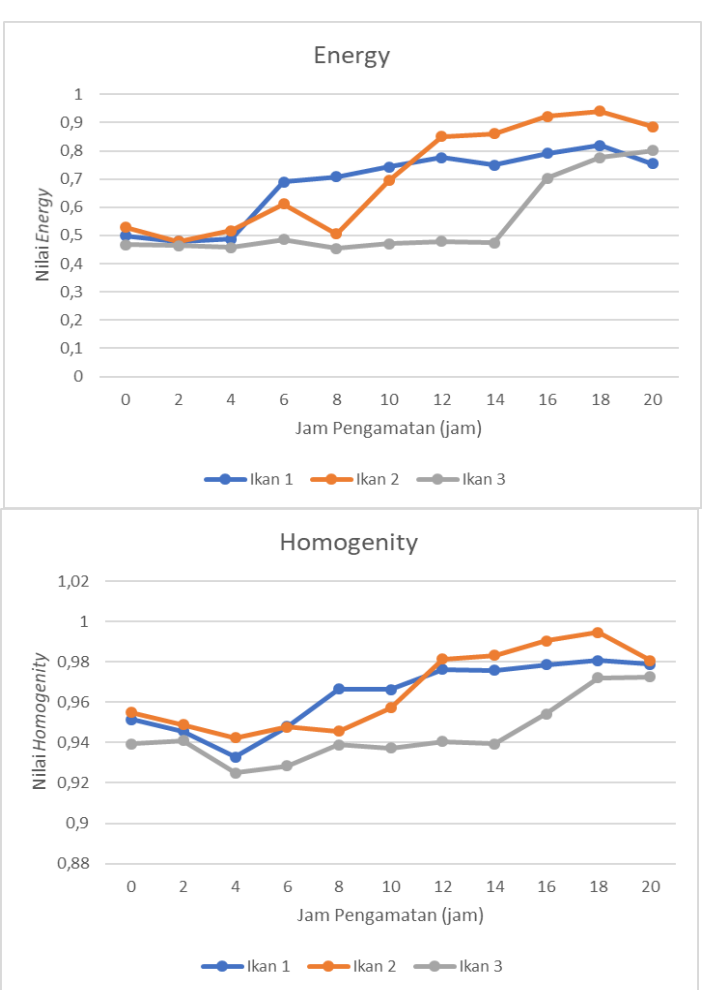

Gambar 3. Tren nilai parameter hasil ekstraksi fitur menggunakan GLCM 
Tabel 1. Hasil analisis regresi nilai masing-masing parameter GLCM

\begin{tabular}{ll}
\hline Fitur GLCM & Koefisien korelasi (R) \\
\hline Contrast & $-0,55$ \\
Correlation & 0,39 \\
Energy & 0,96 \\
\hline Homogenity & 0,95
\end{tabular}

Hasil prediksi menggunakan model algoritma klasifikasi SVM, ANN, dan k-NN ditunjukkan pada Tabel 2. Terlihat bahwa nilai koefisien korelasi dari yan tertinggi adalah k-NN, SVM dan ANN. Semakin tinggi nilai koefisien korelasi maka semakin akurat model klasifikasi tersebut untuk digunakan untuk mempediksi kesegaran ikan tuna. Sebaliknya semakin rendah nilai RMSE maka semakin baik akurasi suatu model klasifikasi.

Tabel 2. Hasil prediksi menggunakan model klasifikasi machine learning

\begin{tabular}{ccc}
\hline Model algoritma & Koefisien korelasi (R) & RMSE (\%) \\
\hline SVM & 0,69 & 4,73 \\
ANN & 0,53 & 5,95 \\
k-NN & 0,83 & 3,75 \\
\hline
\end{tabular}

\section{KESIMPULAN}

Berdasarkan hasil tersebut dapat disimpulkan bahwa metode klasifikasi k-NN adalah metode klasifikasi terbaik yang dapat digunakan untuk memprediksi kesegaran ikan tuna berdasarkan citra mata ikan tuna dengan nilai koefisien korelasi sebesar 0,83 dan RMSE 3,75\%.

\section{DAFTAR PUSTAKA}

Aulia, S., Hadiyoso, S., \& Ramadan, D. N. (2015). Analisis Perbandingan KNN dengan SVM untuk Klasifikasi Penyakit Diabetes Retinopati berdasarkan Citra Eksudat dan Mikroaneurisma. ELKOMIKA: Jurnal Teknik Energi Elektrik, Teknik Telekomunikasi, \& Teknik Elektronika, 3(1), 75.

Brosnan, T., \& Sun, D. W. (2004). Improving quality inspection of food products by computer vision-a review. Journal of food engineering, 61(1), 3-16.

Han, J., Pei, J., \& Kamber, M. (2011). Data mining: concepts and techniques. Elsevier.

Huss, H. H. (1988). Fresh fish--quality and quality changes: a training manual prepared for the FAO/DANIDA Training Programme on Fish Technology and Quality Control (No. 29). Food \& Agriculture Org.

Issac, A., Dutta, M. K., Sarkar, B., \& Burget, R. (2016, February). An efficient image processing based method for gills segmentation from a digital fish image. In 2016 3rd International Conference on Signal Processing and Integrated Networks (SPIN) (pp. 645-649). IEEE.

Kurniawan, Koko. I Made Susi Erawan, (2016). Metode Pengolahan Citra mata untuk Menentukan Kesegaran Ikan Tuna Berbasis Wavelet dan Analisis Tekstur. Seminar Nasional Tahunan XIII Hasil Penelitian Perikanan dan Kelautan. Pasca Panen (pPA - 04), 137-145.

Meenal, R., \& Selvakumar, A. I. (2018). Assessment of SVM, empirical and ANN based solar radiation prediction models with most influencing input parameters. Renewable Energy, 121, 324-343. 
Menesatti, P., Costa, C., \& Aguzzi, J. (2010). Quality evaluation of fish by hyperspectral imaging. In Hyperspectral imaging for food quality analysis and control (pp. 273-294). Academic Press.

Nugraha, M. D., Utama, J. A., \& Sulistiani, S. (2018). Implementasi Metode Random Forest Dalam Memprediksi Peristiwa Flare Di Siklus Ke-23 Dan 24 Menggunakan WEKA Data Mining. Seminar Nasional Fisika (Vol. 4, No. 1, pp. 258-263).

Rahman, A., Kondo, N., Ogawa, Y., Suzuki, T., Shirataki, Y., \& Wakita, Y. (2016). Classification of fresh and spoiled Japanese dace (Tribolodon hakonensis) fish using ultraviolet-visible spectra of eye fluid with multivariate analysis. Engineering in agriculture, environment and food, 9(1), 64-69.

Rohani, A., Taki, M., \& Bahrami, G. (2019). Application of artificial intelligence for separation of live and dead rainbow trout fish eggs. Artificial Intelligence in Agriculture, 1, 2734.

Sudha, L. R., \& Bhavani, R. (2012). Gait based gender identification using statistical pattern classifiers. International Journal of Computer Applications, 40(8), 30-35.

Yapar, A., \& Yetim, H. (1998). Determination of anchovy freshness by refractive index of eye fluid. Food research international, 31(10), 693-695. 